$6-29-2020$

\title{
Modeling E-Textbook Tools or Encouraging Reading from Paper: What are the Effects on Medium Choice and Textbook Use?
}

\author{
Virginia Clinton-Lisell \\ University of North Dakota, virginia.clinton@und.edu \\ Alison E. Kelly \\ University of North Dakota, alison.e.kelly@und.edu \\ Travis D. Clark \\ University of North Dakota, travis.clark@UND.edu
}

\section{How does access to this work benefit you? Let us know!}

Follow this and additional works at: https://commons.und.edu/ehb-fac

Part of the Education Commons

\section{Recommended Citation \\ Virginia Clinton-Lisell, Alison E. Kelly, and Travis D. Clark. "Modeling E-Textbook Tools or Encouraging Reading from Paper: What are the Effects on Medium Choice and Textbook Use?" (2020). Education, Health \& Behavior Studies Faculty Publications. 59. \\ https://commons.und.edu/ehb-fac/59}

This Article is brought to you for free and open access by the Department of Education, Health \& Behavior Studies at UND Scholarly Commons. It has been accepted for inclusion in Education, Health \& Behavior Studies Faculty Publications by an authorized administrator of UND Scholarly Commons. For more information, please contact und.commons@library.und.edu. 
Running head: E-TEXTBOOK TOOLS OR PAPER

Modeling E-textbook Tools or Encouraging Reading from Paper: What are the Effects on Medium Choice and Textbook Use?

Virginia Clinton-Lisell

Alison E. Kelly

Travis D. Clark

University of North Dakota

Author Note

Virginia Clinton-Lisell ORCID ID: https://orcid.org/0000-0002-4705-2217

Correspondence concerning this article should be addressed to Virginia Clinton-Lisell, Educational Foundations and Research, University of North Dakota, 231 Centennial Dr. Grand Forks, ND, 58202, virginia.clinton@und.edu 
Please cite as the following:

Clinton-Lisell, V., Kelly, A.E., \& Clark, T. (in-press). Modeling E-textbook Tools or Encouraging Reading from Paper: What are the Effects on Medium Choice and Textbook Use? College Teaching. http://doi.org/10.1080/87567555.2020.1786665

The version of record is available in College Teaching

http://www.tandfonline.com/10.1080/87567555.2020.1786665 


\begin{abstract}
E-textbooks have become more popular with college students, but there are concerns that reading is not as effective from screens as paper. In addition, students may not take advantage of tools afforded by e-textbooks. The purpose of this study was to determine if encouraging students to read from paper or modeling e-textbook tools would be better for students in terms of reading and using their textbooks. Two instructors randomly assigned students $(N=144)$ to view a video and answer an essay question about either the benefits of reading from paper, how to use etextbook tools, or general information about open educational resources (control). Findings indicated that students told about the benefits of reading from paper were not more likely to read the textbook from paper. Students also generally used both paper and e-textbooks in a similar manner, except students in the e-textbook tools condition reported more notetaking while reading than students in the paper condition. Finally, student medium preference for studying did not change based on condition. Findings from this study provide guidance for how instructors should advise students on reading their course textbooks.
\end{abstract}

Keywords: e-textbooks, open educational resources, reading medium, textbook reading 


\section{Modeling E-textbook Tools or Encouraging Reading from Paper: What are the Effects on Medium Choice and Textbook Use?}

The use of electronic textbooks (e-textbooks) has become more commonplace in postsecondary instruction (deNoyelles \& Raiable, 2017; Florida Virtual Campus, 2016). Etextbooks offer students benefits over traditional paper textbooks, including lower cost and greater convenience. However, robust evidence from three meta-analyses indicates a small performance benefit when reading from paper compared to screens (Clinton, 2019; Delgado et al., 2018; Kong et al., 2018), which could lead instructors to encourage students to use paper textbooks. Further, students typically do not make good use of and are often unaware of tools afforded by e-textbooks, such as searchable annotations and video links (Abaci et al., 2017). This has prompted suggestions for instructor modeling of e-textbook tools for students (van Horne et al., 2016). However, it is uncertain whether such modeling would be more effective than having students read from paper. The purpose of this study was to compare the effectiveness of encouraging paper textbook copies to modeling e-textbook tools on student use of course textbooks and student choice of textbook reading medium.

\section{Literature Review}

\section{Reading Medium}

Three meta-analyses have indicated that reading performance is better from paper than from screens (Clinton, 2019; Delgado et al., 2018; Kong et al., 2018). This benefit of paper appears to be larger for expository text than narrative texts (Clinton, 2019; Delgado et al., 2018), which may be concerning for instructors who assign textbook readings. Although age differences in reading medium differences in performance have not been noted (Clinton, 2019; Delgado et 
al., 2018), college students have been a popular age group for research participants on this topic (Singer \& Alexander, 2017).

College students generally prefer reading from paper rather than reading from screens for their courses (Mizrachi et al., 2018). This preference could explain why college students reported spending more time reading paper textbooks than e-textbooks in a recent study (Abuloum et al., 2019). Further, the reading performance benefit of reading from paper (versus screens) appears to be greatest among students who prefer to read from paper (Lauterman \& Ackerman, 2014). However, college students often choose e-textbooks over paper despite their preference to read from paper, primarily for cost reasons (Clinton, 2018).

One reason college students have for preferring paper textbooks is that they can highlight and take notes more easily in paper textbooks (Millar \& Schrier, 2015). E-textbooks typically have tools that allow for highlighting and notetaking, but students are often either unaware these tools exist or choose not to use them (Junco \& Clem, 2015; van Horne et al., 2016). This may be particularly true for annotation tools, given use of this feature is particularly limited (Junco \& Clem, 2015). However, a study of middle school students found that use of e-textbook features, such as annotations and videos, increased after library instruction on how to find and use these features. This study had a pre-post only design without a control group; therefore, it is possible students would have naturally increased their use of e-textbook features as they used the etextbook in their course (Ragan et al., 2018).

In the current study, the question of whether modeling and encouraging the use of etextbook tools improves student textbook engagement was addressed. Additionally, the current study examined whether this e-textbook tool modeling strategy affects student textbook use more than encouraging students to read from paper. The current study further sought to determine 
whether these two strategies would impact student reading choice medium (paper vs. etextbook). The textbooks for the two courses involved in this study were open educational resources, which are teaching and learning resources in the public domain that are available electronically without access fees (also referred to as open textbooks). These textbooks could be read from paper at a cost considerably lower than that of comparable commercial textbooks.

\section{Expectancy-Value Theory Intervention Use}

The interventions tested in this study were guided by the expectancy-value theory of motivation. According to this theory, one's motivation for a task is determined by whether one expects to be able to engage in the task, as well as how valuable that task is perceived to be (Wigfield \& Eccles, 2000). For example, in order to be motivated to complete mathematics coursework, one would need to view themselves as capable of completing the coursework (expectancy), as well as seeing the coursework as beneficial to their life goals, relevant to their personal lives, or inherently interesting (value). Lacking in either expectancy or value, or both, would likely result in low levels of motivation. However, even if one has high expectancy and value for a task, the cost of the task may have adverse effects on motivation (Barron \& Hulleman, 2015). Cost includes not only financial costs (e.g., the tuition for a course or expense of course materials), but also the effort required for the task, loss of other opportunities necessary to engage in the task, and negative emotions that could arise from the task (Eccles, 2005). Even if one expects to be able to complete a highly-valued task, motivation is low if there is high cost (Jiang et al., 2018).

Numerous educational interventions based on expectancy-value theory have been successfully used to increase students' perceived value of a task (e.g., Harackiewicz et al., 2016; Hulleman et al., 2017). Generally, these interventions target what is termed utility value-which 
is related to the perceived usefulness or personal relevance of a task — by having students learn about how certain tasks or courses are personally meaningful or beneficial to their life goals. These interventions have had positive effects on student motivation in multiple areas, such as mathematics tasks, (Hulleman et al., 2010), college course performance (Hulleman et al., 2017), completion of biology courses (Canning et al., 2018), and engaging in group discussions (Clinton \& Kelly, in press-a; Clinton \& Kelly, in press-b).

\section{The Current Study}

In the current study, the utility value of reading from paper was targeted. In particular, students were provided with information about the performance benefits of reading from paper (e.g., Clinton, 2019; Delgado et al., 2018; Kong et al., 2018), as well as how to obtain paper copies of the textbook. Further, students were told the value of a paper textbook outweighs the costs of money and time necessary to obtain paper copies of the textbook. The purpose of providing this information was to increase the perceived utility value of reading from paper, thereby prompting students to obtain paper copies of their textbook.

A remaining question is whether encouraging students to read from paper or demonstrating how to effectively use e-textbook tools will have a greater impact on textbook engagement. The current study addressed this question with a second intervention in which instructors explained the value of e-textbooks in terms of their tools, such as annotation and video links. This was designed to enhance the perceived usefulness of e-textbooks, and thereby increase student motivation to use their course textbook. This approach is also supported by the technology acceptance model, which suggests that perceived ease of use and perceived usefulness positively predict use of technology (Davis, 1993; for a review see Marangunić \& 
Granić, 2015). Logically, demonstrating to students how to use the e-textbook tools should improve perceived ease of use because students would then know how to find and use the tools.

Bringing these areas together, three research questions guided the current study:

Research question 1: Does encouraging students to read from paper affect the medium from which students report reading? It was hypothesized that students would be more likely to obtain paper versions of their textbook if they learned about the benefit of paper on reading performance, as their perceived value of reading from paper would be increased.

Research question 2: Does encouraging students to use e-textbook tools increase the use of e-textbooks and their tools? It was hypothesized that demonstrating how to use and encouraging use of these tools would lead to greater use of the tools for two reasons. One is that e-textbook tools would be perceived as useful, as the instructor would explain their helpfulness. The second is that the e-textbook tools would be perceived as easier to use because the instructor modeled their use to the students.

Research question 3: Does either encouraging the students to read from paper or using etextbook tools affect how much the textbook is read? It was hypothesized that if students who are encouraged to read from paper do indeed read from paper, then they would use the book more due to the perceived value of reading from paper. It was also hypothesized that students who had e-textbook tools modeled to them would read the e-textbook more.

\section{Method}

\section{Context}

The current study involved two sections, each a different semester, of an on-campus Introduction to Psychology course (162 students in the fall 2019 semester section; 66 students in the Spring 2020 semester section) at a midsized, Midwestern public university. Students in both 
courses were assigned open access introductory psychology textbooks. The fall semester section used an instructor-selected collection of NOBA modules (Biswas-Diener \& Diener, 2016). The spring semester section used an instructor-curated collection of reading from an introduction to psychology open textbook (Introduction to Psychology, 2010), a social psychology open textbook (Principles of Social Psychology, 2010) and NOBA modules (Biswas-Diener \& Diener, 2016). Students in this section were given links to the full online resource, weekly links to specific assigned sections, and customized printable files including all the selected readings covered in the course. To encourage students in both sections to regularly read and use the textbook, the instructors provided weekly extra credit reading note opportunities and wrote many of the quiz and textbook questions based on textbook content.

\section{Participants}

All students in both courses were eligible to complete the pre-intervention and postintervention questionnaires, as well as view the video and complete the syllabus (intervention) quiz for their assigned condition (see Materials and Measures for details). Of the eligible students, 144 completed the necessary experimental tasks (intervention essay question and postintervention questionnaire) for inclusion in this study. Demographic reporting was optional. Based on the self-reports of 139 participants, the average age was $18.59(S D=1.22$ years $)$. One hundred and thirty-four students reported their high school grade point averages, with a mean of 3.70 on a 4.00 scale $(S D=.34)$. In terms of gender identity, $29.8 \%$ reported being men, $.6 \%$ did not report a gender identity, and $69.6 \%$ reported being women. Of the participants who reported their racial identity(ies), 80.9\% reported being White/Caucasian, 2.5\% reported Asian, 1.8\% reported Native American or Pacific Islander, 1.3\% reported African American, and 13\% reported multiple racial identities. 


\section{Materials and Measures}

Intervention and control materials. For the paper condition, a video was designed explaining the research findings on the reading performance benefit of paper compared to screens. The video also presented options for paper versions of the textbook and provided students with links for how to order paper versions. For the e-textbook tools condition, students were shown how to annotate and highlight their textbook. They were also shown the video links feature. In the control condition, students were presented with information about what open educational resources (OER) are and research findings supporting the use of OER. Students were told they could read the book either electronically or obtain a paper copy but were not advised regarding which medium they should read from or how they should read the course textbook. Each of the videos was recorded by the course instructor and posted on the course learning management site (Blackboard). Students were only able to view the video condition they were randomly assigned to on their site.

After viewing their assigned video, students took a required quiz. For all conditions, the quiz had the same 8 multiple-choice items covering the syllabus, but the last item in the quiz was an open-ended item that varied by condition. Students in the paper condition and the e-textbook tools condition answered the prompt "Write two paragraphs summarizing the information in this video and how you will use the information in this video to help you read the textbook for the course." Students in the control condition answered the prompt "Write two paragraphs about the information covered in this video."

Pre-intervention questionnaire. This questionnaire was adapted from the Mizrachi and colleagues (2018) survey of academic reading format preferences. There were eight items assessing medium preferences in which students indicated their agreement on a five-point Likert 
scale (Cronbach's $\alpha=.84$ ). Higher scores indicate a greater preference for paper over screens for reading. Students were also asked whether they preferred to study from screens, paper, or either and whether they had typically used paper textbooks, electronic textbooks or a mix of paper and electronic textbooks in previous classes. Demographic and other background information such as gender identity, racial/ethnic identities, age, high school grade point average, and native language were also requested.

Post-intervention questionnaire. This questionnaire included items about textbook use adapted from Clinton (2018). There were six items about textbook reading and behaviors in which students indicated their agreement on a five-point Likert scale (see Table 3 for means and standard deviations for each item). In addition, students were asked to estimate the percentage of assignment reading they complete using a slider scale from 0-100 and how many minutes per week they read (open response). Students were also asked whether they typically read their textbook on paper, screen, or a mix of paper and screens.

\section{Procedure}

During the first week of the semester, the instructor invited students to complete the preintervention questionnaire in order to establish a baseline of medium preference prior to the intervention. Once the pre-intervention questionnaire was closed, students were randomly assigned to condition through the course learning management site to view the video and prompt for their condition. During the seventh week of the semester, students were invited to complete the post-intervention questionnaire about their use of the textbook. Participation for both the preand post-intervention questionnaires was voluntary and students received extra credit upon completion of the questionnaires.

\section{Results}


To examine possible differences in reading medium preference and previous experience with e-textbooks prior to the intervention, three tests were conducted. The first was a one-way ANOVA with condition as the independent variable and academic reading format preference (continuous scale) as the dependent variable. There were no reliable differences by condition, $F(2,140)=1.12, p=.27$ (paper: $M=3.63, S D=.81$; e-textbook tools: $M=3.84, S D=.62$; control: $M=3.61, S D=.69)$. Two Pearson chi-square tests were also conducted. One examined preferred study medium (paper, screen, or either) and found no reliable differences by condition, $\chi^{2}(4)=5.54, p=.24$. There were also no reliable a priori differences between conditions based on whether previously used textbooks had been paper, electronic, or a mixture of both, $\chi^{2}(4)$ $=3.31, p=.51$. See Table 1 for distributions of study medium preference and textbook medium typical use by conditions. Note that three of the students who completed the post-intervention questionnaire did not complete the pre-intervention questionnaire.

\section{Table 1}

\section{Pre-intervention preferred study medium and typical textbook medium distributions by condition}

Preferred study medium

Condition

\begin{tabular}{lllll}
\hline & Paper & E-textbooks Tools & Control & Total \\
& & & & \\
\hline Paper & 38 & 33 & 31 & 102 \\
\hline Screen & 5 & 2 & 3 & 10 \\
\hline Either & 8 & 6 & 15 & 29 \\
\hline Total & 51 & 41 & 49 & 141 \\
\hline
\end{tabular}


Typical textbook medium

\section{Condition}

\begin{tabular}{lcccc}
\hline & Paper & E-textbooks Tools & Control & Total \\
& & & & \\
\hline Paper & 16 & 17 & 12 & 45 \\
\hline Electronic & 3 & 2 & 2 & 7 \\
\hline Mixed & 32 & 22 & 35 & 89 \\
\hline Total & 51 & 41 & 49 & 141 \\
\hline
\end{tabular}

To address the first research question regarding the effects of condition on textbook medium choice, a chi-square test with condition and medium choice (paper, screen, or a mix) was conducted. There was no reliable effect of condition, $\chi^{2}(4)=3.74, p=.44$, indicating that informing students about the benefits of reading from paper did not affect their decision to read the textbook from paper. As can be seen in Table 2, a clear majority of the students read the textbook electronically. 


\title{
Table 2
}

\section{Post-intervention textbook reading medium and study preference medium by condition}

Textbook medium used for the course

\author{
Condition
}

Paper E-textbook Tools Control Total

\begin{tabular}{lllll}
\hline Paper & 0 & 1 & 1 & 2 \\
\hline Screen & 47 & 40 & 49 & 136 \\
\hline Mixed & 4 & 1 & 1 & 6 \\
\hline Total & 51 & 42 & 51 & 144 \\
\hline
\end{tabular}

To address the second research question about textbook use, a series of one-way ANOVAs were conducted, with condition as the independent variable and responses to the items about textbook use as the dependent variables. As can be seen in Table 3, there were generally no reliable differences in reported textbook use among conditions, except for notetaking while reading. Follow up post-hoc comparisons were conducted using Tukey corrections. Students in the e-textbook tools condition reported more notetaking while reading than did students in the paper condition (Cohen's $d=.51, p=.047)$. However, there were no reliable differences in reported notetaking between students in the e-textbook tools and control conditions $(p=.74)$ or the paper and control conditions $(p=.20)$.

To address the third research question related to the amount of reading, two one-way ANOVAs were conducted, with condition as the independent variable and percentage of 
assigned reading completed and minutes of reading per week as the dependent variables. As can be seen in Table 3, there were no reliable differences for either of the reading variables.

Table 3

Textbook use and reading amount by condition

\begin{tabular}{|c|c|c|c|c|}
\hline Item & $\begin{array}{l}\text { Paper } \\
\text { M(SD) }\end{array}$ & $\begin{array}{l}\text { Electronic } \\
\text { Tools } \\
\text { M(SD) }\end{array}$ & $\begin{array}{l}\text { Control } \\
\text { M(SD) }\end{array}$ & $F$ \\
\hline $\begin{array}{l}\text { I read before } \\
\text { lectures. }\end{array}$ & $2.55(1.27)$ & $2.55(1.23)$ & $2.57(1.25)$ & .004 \\
\hline $\begin{array}{l}\text { After lecture, I } \\
\text { use the book to } \\
\text { help me } \\
\text { understand what } \\
\text { was covered in } \\
\text { lecture. }\end{array}$ & $2.82(1.18)$ & $3.00(1.19)$ & $2.98(1.35)$ & .30 \\
\hline $\begin{array}{l}\text { I use the } \\
\text { textbook to help } \\
\text { me prepare for } \\
\text { exams. }\end{array}$ & $3.51(1.35)$ & $3.64(.93)$ & $3.69(1.18)$ & .31 \\
\hline $\begin{array}{l}\text { I use the book to } \\
\text { understand what } \\
\text { was covered } \\
\text { when I miss } \\
\text { lecture. }\end{array}$ & $3.69(1.29)$ & $3.69(1.16)$ & $3.57(1.10)$ & .17 \\
\hline $\begin{array}{l}\text { I take notes as I } \\
\text { read the } \\
\text { textbook. }\end{array}$ & $2.82(1.28)$ & $3.48(1.25)$ & $3.27(1.39)$ & $3.09 *$ \\
\hline $\begin{array}{l}\text { I highlight or } \\
\text { underline as I } \\
\text { read. }\end{array}$ & $3.48(1.25)$ & $2.82(1.28)$ & $3.27(1.39)$ & 1.64 \\
\hline $\begin{array}{l}\text { Percentage of } \\
\text { assigned reading } \\
\text { read }\end{array}$ & $55.80(30.13)$ & $52.95(28.97)$ & $58.63(31.98)$ & .40 \\
\hline $\begin{array}{l}\text { Minutes per } \\
\text { week reading the } \\
\text { textbook }\end{array}$ & $47.54(34.57)$ & $54.56(50.03)$ & $56.82(62.72)$ & .46 \\
\hline
\end{tabular}

\section{Discussion}


The purpose of this study was to examine the effectiveness of encouraging students to read e-textbooks on paper versus showing them how to use e-textbook tools. Based on the results, encouraging students to obtain a paper copy of their e-textbook and providing guidance for how to do so did not have any effect on students' reported choice of reading medium. On the other hand, students who were shown how to use e-textbook tools reported more notetaking while reading compared to students who were encouraged to read their textbook on paper. Otherwise, students generally used and read their textbooks in similar ways across conditions.

Less than six percent of the students in this study reported reading any of their textbook from paper. This was despite most reporting a preference for reading from paper, as well as students in the paper condition being informed of the potential benefits of reading from paper over screens. One interpretation of these findings is that although students perceived value in paper over screens, the cost of effort and money to obtain paper outweighed that value (Barron $\&$ Hulleman, 2015). The textbooks used in this study were free to access electronically and were posted on the courses' learning management sites, likely making it convenient to read. Students in the paper condition were informed of options for reading from paper; however, these options all involved more cost than reading electronically.

Students who were encouraged to use the e-textbook tools generally used the textbook similarly to students in other conditions in terms of reading to understand the course content and to prepare for exams. However, students who were encouraged to use the e-textbook tools reported more notetaking while reading than students who were encouraged to read from paper. Because most of the students read the textbook from a screen, it is unlikely this finding was due to differences in notetaking in different media, as was found in previous work (e.g., Junco \& Clem, 2015; van Horne et al., 2016). Therefore, the current study provides some evidence that 
instructor scaffolding of e-textbook tools may help student reading strategies. As would be supported by the technology acceptance model (Davis, 1993), in addition to expectancy-value theory (Wigfield \& Eccles, 2000), this finding may be the result of perceived ease of use for the tools after having the instructor model the tools, as well as perceived value after the instructor explained how helpful the annotation tool was. However, we did not assess perceived ease of use or value of e-textbook tools because we had hypothesized a substantial portion of the students in this study would read from paper and subsequently not be aware of or able to use these tools. Therefore, these explanations are based on theories rather than empirical data. Examining the effects of instructor modeling of tools on perceived use and value would be an informative future avenue for research.

In terms of quantity of reading, students read their course textbooks at similar rates both for minutes of reading per week and percentage of assigned reading completed. This is somewhat reassuring given there were concerns that students who were encouraged to read from paper, but opted to read from a screen would engage with their textbook less because it would be perceived as less helpful. However, there did not seem to be evidence that students who were encouraged to use the e-textbook tools read more to reap the benefits of these tools.

\section{Limitations}

As with all studies, there are limitations that should be acknowledged. This study involved two sections of the same course at a single institution. The students were fairly homogenous in terms of demographics. It is uncertain how these findings would generalize to other institutions and student populations. More studies are needed to examine the generalizability of these interventions before there can be confidence in their effects (or lack thereof). This is particularly true for the finding regarding notetaking given that it was the only 
statistically reliable effect of the interventions and there was not a difference between the etextbook tools and control conditions.

The textbooks used in the courses for this study were electronically available without access fees, but did cost money for the printed paper versions. It is possible that commercial textbooks that cost money for either electronic or paper versions would yield different results. Previous findings have indicated that products that are free are more appealing to college students than products that are low cost, even if the actual cost savings would be greater with some payment (Delargy, 2011). For example, one study found that when offered a choice between two chocolates that vary in appeal, students tended to overwhelmingly select the less appealing chocolate when it was free and the more appealing chocolate was 25 cents (Ariely \& Shampan'er, 2006). However, when the price of both chocolates increased by one cent, students chose the two chocolates at equal rates. Although the price difference was identical in the two scenarios, the authors concluded the price of free is compelling to consumers (Ariely \& Shampan'er, 2006). An interesting idea for future research would be to assess the effects of these interventions on course materials that incur financial cost for any medium.

\section{Conclusions}

The growing popularity of e-textbooks coupled with research findings indicating a small benefit of reading from paper over screens may have instructors wondering how to best guide their students' medium choice and use of course textbooks (Clinton, 2019; Delgado et al., 2018; Kong et al., 2018). The current study tested whether it is better for instructors to encourage students to read from paper or to model the use of e-textbook tools. The findings from this study indicated that students opted to read their e-textbook from a screen rather than take the steps to obtain paper versions. However, modeling annotation e-textbook tools appeared to promote 
notetaking while reading the textbook. Students otherwise used and read their textbook in similar manners whether their instructor encouraged them to read from paper or use e-textbook tools. 


\section{References}

Abuloum, A. M., Farah, A., Kaskaloglu, E., \& Yaakub, A. (2019). College Students' Usage of and Preferences for Print and Electronic Textbooks. International Journal of Emerging Technologies in Learning (iJET), 14(7), 80-97. https://doi.org/10.3991/ijet.v14i07.9871

Ariely, Dan and Shampan'er, Kristina, How Small is Zero Price? The True Value of Free Products (October 2006). FRB of Boston Working Paper No. 06-16. http://dx.doi.org/10.2139/ssrn.951742

Barron, K. E., \& Hulleman, C. S. (2015). Expectancy-value-cost model of motivation. In J. D.Wright (Ed.), International encyclopedia of the social \& behavioral sciences (2nd ed., Vol. 8, pp. 503-509). Oxford, UK: Elsevier Ltd. http://dx.doi.org10.1016/B978-0-08097086-8.26099-6

Canning, E. A., Harackiewicz, J. M., Priniski, S. J., Hecht, C. A., Tibbetts, Y., \& Hyde, J. S. (2018). Improving performance and retention in introductory biology with a utility-value intervention. Journal of Educational Psychology, 110(6), 834-849. https://doi.org/10.1037/edu0000244

Clinton, V. (2018). Savings without sacrifice: a case report on open-source textbook adoption. Open Learning: The Journal of Open, Distance and e-Learning, 33(3), 177189. https://doi.org/10.1080/02680513.2018.1486184

Clinton, V. (2019). Reading from paper compared to screens: A systematic review and metaanalysis. Journal of Research in Reading, 42(2), 288-325. https://doi.org/10.1111/1467$\underline{9817.12269}$ 
Clinton, V., \& Kelly, A. E. (in press-a). Improving student attitudes toward discussion boards using a brief motivational intervention. Scholarship of Teaching and Learning in Psychology. Advance online publication. https://doi.org/10.1037/st10000160

Clinton, V., \& Kelly, A. E. (in press-b). Student attitudes toward group discussions. Active Learning in Higher Education. https://doi.org/10.1177/1469787417740277.

Davis, F. D. (1993). User acceptance of information technology: system characteristics, user perceptions and behavioral impacts. International Journal of Man-Machine Studies, 38(3), 475-487. https://doi.org/10.1006/imms.1993.1022

Delargy, C. (2011). The Popularity and Valuation of Free Products in an Undergraduate Student Population. Student Psychology Journal, 2, 3-20. https://psychology.tcd.ie/spj/past_issues/issue02/Empirical\%20Studies/(1)\%20Clare\%20 Delargy.pdf

Delgado, P., Vargas, C., Ackerman, R., \& Salmerón, L. (2018). Don't throw away your printed books: A meta-analysis on the effects of reading media on reading comprehension. Educational Research Review, 25, 23-38. https://doi.org/10.1016/j.edurev.2018.09.003

deNoyelles, A., \& Raible, J. (2017). Exploring the use of e-textbooks in higher education: A multiyear study. Educause Review. Retrieved from https://er.educause.edu/articles/2017/10/exploring-the-use-of-e-textbooks-in-highereducation-a-multiyear-study

Biswas-Diener, R., Diener, E. (Eds.). (2016). Introduction to psychology: The full Noba collection. DEF Publishers. Retrieved from www.nobaproject.com 
Eccles, J. S. (2005). Subjective task values and the Eccles et al. model of achievement-related choices. In A. J. Elliot \& C. S. Dweck (Eds.), Handbook of competence and motivation (pp. 105-121). New York, NY: Guilford.

Florida Virtual Campus. (2016). 2016 Florida Student Textbook Survey. Tallahassee, FL: Author.

Harackiewicz, J. M., Canning, E. A., Tibbetts, Y., Priniski, S. J., \& Hyde, J. S. (2016). Closing achievement gaps with a utility-value intervention: Disentangling race and social class. Journal of Personality and Social Psychology, 111(5), 745-765. https://doi.org10.1037/pspp0000075

Hulleman, C. S., Godes, O., Hendricks, B. L., \& Harackiewicz, J. M. (2010). Enhancing interest and performance with a utility value intervention. Journal of Educational Psychology, 102(4), 880-895. https://doi.org/10.1037/a0019506

Introduction to Psychology (2010). University of Minnesota Libraries Publishing. https://open.lib.umn.edu/intropsyc/

Jiang, Y., Rosenzweig, E. Q., \& Gaspard, H. (2018). An expectancy-value-cost approach in predicting adolescent students' academic motivation and achievement. Contemporary Educational Psychology, 54, 139-152. https://doi.org/10.1016/j.cedpsych.2018.06.005

Kong, Y., Seo, Y. S., \& Zhai, L. (2018). Comparison of reading performance on screen and on paper: A meta-analysis. Computers \& Education, 123, 138-149. https://doi.org/10.1016/j. compedu.2018.05.005

Lauterman, T., \& Ackerman, R. (2014). Overcoming screen inferiority in learning and calibration. Computers in Human Behavior, 35, 455-463. https://doi.org/10.1016/j.chb.2014.02.046 
Junco, R., \& Clem, C. (2015). Predicting course outcomes with digital textbook usage data. The Internet and Higher Education, 27, 54-63. https://doi.org/10.1016/j.iheduc.2015.06.001

Marangunić, N., \& Granić, A. (2015). Technology acceptance model: a literature review from 1986 to 2013. Universal Access in the Information Society, 14(1), 81-95. https://doi: https://doi.org/10.1007/s10209-014-0348-1

Millar, M., \& Schrier, T. (2015). Digital or printed textbooks: which do students prefer and why?. Journal of Teaching in Travel \& Tourism, 15(2), 166-185. https://doi.org/10.1007/s10209-014-0348-1

Mizrachi D, Salaz AM, Kurbanoglu S, Boustany J, on behalf of the ARFIS Research Group (2018) Academic reading format preferences and behaviors among university students worldwide: A comparative survey analysis. PLoS ONE, 13(5): e0197444. https://doi. org/10.1371/journal.pone.0197444

Principles of Social Psychology (2010). University of Minnesota Libraries Publishing. https://open.lib.umn.edu/socialpsychology/

Ragan, A., Kammer, J., Atkins, C. and Burress, R. (2019), "Learning to read online: the effect of instruction on e-textbook use", Library Hi Tech, 37(2), 293-311. https://doi.org/10.1108/LHT-01-2018-0011

Singer, L. M., \& Alexander, P. A. (2017). Reading on paper and digitally: What the past decades of empirical research reveal. Review of Educational Research, 87(6), 1007-1041. https://doi: 10.3102/0034654317722961

Van Horne, S., Russell, J. E., \& Schuh, K. L. (2016). The adoption of mark-up tools in an interactive e-textbook reader. Educational Technology Research and Development, 64(3), 407-433. https://doi.org/10.1007/s11423-016-9425-X 
Wigfield, A., \& Eccles, J. S. (2000). Expectancy-value theory of achievement motivation. Contemporary Educational Psychology, 25(1), 68 - 81. https://doi:10.1006/ceps.1999.1015 